\title{
Understanding the Effects of Urban Form and Navigational Aids on Wayfinding Behaviour and Spatial Cognition
}

\author{
Sima Vaez ${ }^{\star}$ \\ Cities Research Institute, \\ Griffith University, \\ Brisbane, Australia
}

\author{
Matthew Burke \\ Cities Research Institute, \\ Griffith University, \\ Brisbane, Australia
}

\author{
Rongrong Yu \\ Cities Research Institute, \\ Griffith University, \\ Gold Coast, Australia
}

\section{INTRODUCTION}

The term wayfinding describes a person's ability, both cognitive and behavioral, to travel from an origin to an out-of-sight destination by following the paths and routes between them (Garling et al., 1984; Golledge, 1992). Successful wayfinding helps travelers gain a sense of safety and well-being (Lu, 2016). So, different disciplines, such as transport planning (Dutriaux \& Gyselinck, 2016), psychology (Gras et al., 2012), architecture (Passini, 1984), and urban design and planning (Lynch, 1960), have sought to understand how people make sense of their surrounding environment when navigating.

In cognitive studies, different researchers use the two terms 'cognition' and 'perception' to describe a human's ability to acquire knowledge of the physical environment surrounding them (Yadav, 1987). The term cognition has a much broader meaning than simply describing perception. Regarding the spatial cognition process, first, environmental information is encoded by the human mind (perception) and then the information is processed using different cognitive resources (conception), stored in the long-term memory, and eventually retrieved and applied for a particular purpose such as wayfinding (Vandenberg, 2016).

However, the use of navigational aids, such as directional signage or maps, has made the wayfinding process much easier for urban navigators. This study aims to explore the effects of three different navigational aids, such as paper maps, GPS, and directional signages, on individuals' spatial cognition and wayfinding behavior.

Lynch (1960) argued that observation of environmental cues while navigating in an urban environment creates a mental image in an indivi-

\section{Abstract /}

In an age in which navigators can simply follow the represented route on their smartphone to get to their desired destination, is there any need for signage and urban legibility? This study aims to explore the effects of urban form and different navigational aids on visitors' spatial cognition and wayfinding behavior. Thirty-eight participants were placed in one of three groups: i) a paper map only; ii) smartphones with the Google Maps app; and, iii) no navigational aids (local signage only). Participants were asked to find six pre-determined tourist destinations in central Brisbane, Australia, while they were thinking aloud. Post-task tests showed that participants in the group without personal navigational aids were more successful in landmark recognition than map users. Those who used paper maps performed best in route accuracy and street-naming tests. However, across all the spatial recognition tests, the GPS group was systematically neither the best nor the worst in terms of acquired spatial knowledge. The findings have the potential to assist urban designers and navigational mapping producers to design more legible urban spaces and more effective wayfinding tools. Keywords /

wayfinding; spatial cognition; navigational aids; urban legibility; think-aloud technique 
dual's mind which he called a "cognitive urban image." During wayfinding activities, the spatial visualization ability of navigators assists them to use their stored spatial information through a decision-making process (Li, 2007). This ability varies among individuals (Hegarty \& Waller, 2005), and people might have different perceptions about the same environment depending on their personal characteristics, such as age (Techentin et al., 2014), brain size (Rushton \& Ankney, 1996), and sex (Goede, 2009).

In spite of individual differences in spatial cognition processes, Lynch (1960) suggested that one's mental image of an urban environment can be understood as consisting of five key elements: landmarks, paths, nodes, edges, and districts. Landmarks are distinctive features that by their uniqueness make them memorable in urban users' minds. If they are observable from near and far, they play the role of reference points during navigation through an urban environment (Lindberg, 1984; Lynch, 1960). 'Paths', including sidewalks and streets, provide directional movement through urban environments for navigators. 'Edges' are certain boundaries surrounding a particular district with a continuous, certain form, such as rivers or highways. The junction of paths forms 'nodes' that tend to be more identifiable if they have sharp and closed boundaries and can be used as public spaces. "Districts" are large areas that have homogeneous characteristics, including physical characteristics such as color, texture, façades of buildings, materials and patterns of pavement, that consciously can be observed in one district area (Lynch, 1960). A legible (or imageable) city has these elements grouped into a somewhat coherent overall pattern.

Following Lynch's ideas, Siegel and White (1975) defined three types of spatial knowledge that humans use to create cognitive maps: landmark knowledge - using pointlike elements of the environment; route knowledge - using line-like elements; and survey knowledge, which encodes the metric information about the layout of space (Golledge, 1987). For example, when a woman arrives in an unfamiliar city she may decide to have dinner in a restaurant on her way from the airport to the hotel. In order to recall the location of this restaurant, she would memorize the fact that it was after the park and around the corner from a particular statue.
After using this method several times to search for and find the restaurant, she will begin to use route knowledge (Dillon \& Vaughan, 1997). Route knowledge refers to the spatial knowledge that is acquired by traveling from an origin to a destination, using existing paths that connect the landmarks. It is based on the knowledge acquired by traveling from $A$ to $B$ through paths that connect landmarks and places (Siegel et al., 1978; Thorndyke \& Hayes-Roth, 1982), and consequently developing a path network. The most often used path segment is represented by lines in cognitive maps (Golledge, 1978). Now, our abovementioned woman begins to make sense of the location of her hotel. She knows that the hotel is near the corner and up that particular road. After visiting her chosen restaurant several times, she will begin to make sense of existing environmental features - in two or three-dimensional layouts - on her way from the restaurant to the hotel. In other words, she begins using her previously observed/survey knowledge to generate a mental map of that environment (Golledge, 1999). Survey knowledge is based on coordinating different routes between landmarks and the estimation of the Euclidean distance between them, while creating a cognitive map (Siegel et al., 1978; Thorndyke \& Hayes-Roth, 1982). Wayfinding performance could be affected by using each of these forms of knowledge (Meneghetti et al., 2021); for example,'go straight on (route) until you see the city tower (landmark) and then turn left. Better understanding of how navigators make sense of their surrounding environment could be used by urban designers and navigational aids designers to improve the legibility of urban environments as well as the effectiveness of wayfinding systems.

The advent of technology and the use of GPS-based mobile navigation systems have brought forth new forms of interaction between individuals and the surrounding environment, whether they drive a vehicle or walk (Grison \& Gyselinck, 2019). Several previous studies have compared the use of different navigational tools with acquired spatial knowledge, whether in indoor space (Hölscher et al., 2007; Thorndyke \& Hayes-Roth, 1982), outdoor space (Chang, 2015; Ishikawa et al., 2008; Münzer et al., 2006) or virtual environments (Ruginski et al., 2019).

Ishikawa et al. (2008) examined the effectiveness of a Global Positioning System (GPS)-based mobile naviga- 
tion system when compared to paper maps and direct experience of routes by focusing on the user's wayfinding behavior and acquired spatial knowledge. They found that the distance travelled and the number of stops for the GPS group were significantly larger than map users and direct-experience participants. In addition, the GPS users walked more slowly, made more directional mistakes, and drew less accurate sketch maps in terms of topological accuracy, than the direct-experience group. Later, Chang (2015) conducted a similar study, comparing the wayfinding efficiency and behaviour of international tourists when using a mobile navigation aid or a paper map and local directional signs. Her study found that sketch maps drawn by participants who used the local signs for wayfinding provided more detailed information/landmarks, and their drawn walking routes were more accurate than those of map users and GPS users. But GPS users remembered more information regarding transportation and route/ road items, such as road names and the entire travel route.

\section{RESEARCH OBJECTIVES}

This study aims to confirm the findings of previous studies (Chang, 2015; Ishikawa et al., 2008) in terms of the difference in acquired spatial knowledge that occurs from the use of three different navigational aids, such as those used in our study, in an outdoor setting, and to understand why these differences occur. In addition, it seeks to gain better understanding of how key features of the urban environment contribute to urban legibility/imageability. Two basic hypotheses are measured in this study:

H1: Spatial knowledge acquisition, when navigating the same urban environment, varies based on the type of navigational aid used.

H2: $\quad$ That looking at a GPS-based navigational device would decrease navigators' engagement with their surrounding environment.

Better understanding of the role of navigational aids and how realworld navigators acquire spatial knowledge when using them may assist urban designers and wayfinding practitioners to develop better wayfinding signage approaches and systems and could also assist app-developers to produce improved navigational aids, particularly for GPS-based devices.

\section{RESEARCH DESIGN}

\section{Participants}

Thirty-eight students from Griffith University's Gold Coast Campus, 15 men and 23 women, were recruited through emails and posters on campus, based on the following criteria: $a$ ) be over 17 years old, $b$ ) be unfamiliar 
with the Brisbane CBD, c) speak English well. They ranged in age from 18 to 56 years old, with a mean of 26.8 years, and a standard deviation of 8.5. All were unfamiliar with the study area and travelled at least $70 \mathrm{~km}$ from the Gold Coast to central Brisbane by train and met the experimenter at Roma Street Station to undertake the wayfinding tasks. The travel costs from the Gold Coast to Brisbane were reimbursed; in addition, they received $\$ 50$ incentive payment.

To minimize the impact of potential confounding variables, the socio-demographic characteristics of the groups, such as gender, age, degree and nationality, were controlled using statistical ANOVA testing (Table 1). There was no significant difference in terms of demographic features among the three groups of participants. Participants' sense of direction was assessed using a Santa Barbara Sense of Direction (SBSOD) scale, and no significant differences were identified.

Table 1 / Summary of personal characteristics across the independent groups

\begin{tabular}{|c|c|c|c|c|c|}
\hline \multicolumn{2}{|c|}{ Socio-economic Characteristics } & \multicolumn{4}{|c|}{ Navigational Aid Type } \\
\hline & & $\begin{array}{l}\text { Signage } \\
(\mathrm{N}=14)\end{array}$ & $\begin{array}{l}\text { Map } \\
(\mathrm{N}=12)\end{array}$ & $\begin{array}{l}\text { GPS } \\
(\mathrm{N}=12)\end{array}$ & P Value \\
\hline \multirow[t]{2}{*}{ Gender } & Male & 5 & 5 & 5 & \multirow[t]{2}{*}{0.29} \\
\hline & Female & 9 & 7 & 7 & \\
\hline \multirow[t]{2}{*}{ Age } & $\begin{array}{l}\text { Range } \\
\text { (Min-Max) }\end{array}$ & $18-34$ & $18-56$ & $18-46$ & NA \\
\hline & Mean & 24.2 & 28 & 28.9 & 0.39 \\
\hline \multirow[t]{3}{*}{ Degree } & $\begin{array}{l}\text { High School } \\
\text { Diploma }\end{array}$ & 6 & 4 & 3 & \multirow[t]{3}{*}{0.57} \\
\hline & Bachelor & 5 & 3 & 5 & \\
\hline & Master & 2 & 5 & 4 & \\
\hline \multirow{2}{*}{$\begin{array}{l}\text { Country of } \\
\text { origin }\end{array}$} & Australian & 5 & 4 & 4 & \multirow[t]{2}{*}{0.98} \\
\hline & Non-Australian & 9 & 8 & 8 & \\
\hline
\end{tabular}

To control membership of the sampled groups, partly taking into consideration their own preferences, the participants were assigned to one of three groups: i) a group using Google Maps ( $n=12)$; ii) a group using a conventional 2D paper map ( $n=12)$; and iii) a group with no aids other than the local signage that is already in place in the built environment $(n=14)$. A briefing session was held prior to the experiment day, at which all participants were informed of the aims, procedures, and requirements of the research, particularly the parts related to the think-aloud and sketch mapping techniques. Without referring to the urban elements identified by Lynch, they were informed that after the test they would need to draw their mental image of the observed environment, and some samples of sketch maps were shown. Participants' sense of direction was assessed using a Santa Barbara Sense of Direction (SBSOD) scale, and they were asked which group they preferred to be in. If membership in their first preference was not possible, they were assigned to their second preference. All participants 
were assigned to their first or second preference group. On the experiment day, participants were informed about the destinations.

\section{Study Area}

The Brisbane central business district (CBD) and the South Bank precinct, being the two most popular sightseeing areas in Brisbane, were chosen as the study area (see Figure 1). The participants were asked to individually find six pre-determined destinations in the study area, in any order, these being: the Brisbane City Hall, the Queen Street Mall, St. Stephen's Cathedral, South Bank Beach, South Bank Railway Station, and the COWCH Café Bar in South Bank. The list of destinations was written on a piece of paper and given to them.

\section{DATA COLLECTION PROCEDURE}

\section{Wayfinding Task}

The starting point was the Roma Street Station, where the participants' train arrived. The final meeting point was at $\mathrm{COWCH}$ café, where post-test tasks occurred.

A Samsung Galaxy J5 Mobile phone equipped with $3 \mathrm{G}$ service and the Google Maps app was given to the GPS group. The map of the surrounding area was shown on a screen size of $14 \mathrm{~cm} \times 7 \mathrm{~cm}$. The app showed the location of the user on the screen, and dynamically updated as they moved in the area. Participants were asked not to use the voice navigation option.

Participants in the paper map and local-signage only groups were also given smartphones, but only to record audio of their speech and to capture GPS tracks of their movement, and they were instructed not to use them as a navigational aid. The route tracker application Geotracker was installed on the same smartphone and recorded the length of time taken by all participants, as well as the route travelled. Participants in the paper map group were given an A4-size tourist map of Brisbane, as provided by tourist information centres in the city. There was no suggested route or other annotation on the map and they had to find the destinations and plan their preferred routes by themselves.

All groups were instructed to only ask other people for help if they were unable to navigate via their navigational aid, or the built evironment, without assistance. All groups were asked to think aloud and verbalize their thoughts, in English, about the wayfinding process, the buildings, streets, the signs, the maps, their feelings, and whatever else they saw or that came to their minds.

\section{Think-aloud}

The think-aloud method (Ericsson \& Simon, 1980) was employed to help identify differences in wayfinding behavior across the three groups of participants who used different navigational aids. Participants were asked to vocalize their thoughts continuously while solving the wayfinding task. This provided rich verbal data about individuals' reasoning, what they saw and how they felt during wayfinding. The think-aloud method is

The map of the study area 
well-used in wayfinding research (Hölscher et al., 2009; Hölscher et al., 2006; Kato \& Takeuchi, 2003; Passini, 1984; Schnitzler \& Hölscher, 2015; Vaez et al., 2019). All recordings were transcribed by a research assistant. After transcription, the participants' statements were segmented, with one segment of utterance defined as the continuous statement which occurs between two pauses (Kato \& Takeuchi, 2003). Two rounds of coding were then conducted by a single researcher with a time interval of two weeks (Yu \& Gero, 2015). Participants' reasons for choosing a street segment, or any side of the street, during navigation were extracted from the think-aloud protocols, as well as the names of landmarks perceived by them. Krippendorff's a (alpha) statistics suggested that the two rounds of coding had a good agreement $(a \geq 0.8)$.

\section{Sketch mapping and recognition test}

Using Lynch's (1960) approach, the participants were asked to draw and write down as much information as they could remember, such as streets, buildings, landmarks, parks, transport stations, etc., solely from memory and without referring to any other paper or digital map. To overcome the problem of individuals' lack of drawing ability, a spatial recognition test (Piaget \& Inhelder, 1967) was also taken after collecting participants' sketch maps. For the test, the participants were shown photos of five buildings and landmarks in the study area, and they were asked to write down the number of photos that they could clearly identify.

\section{Sketch mapping follow-up interview}

To gain more insight into how visitors developed a mental image of space and the role of navigational aids in that process, participants were asked to write their answers to the following questions, which were written and read to them:

- Why did you remember and draw certain streets on the sketch map (i.e. what were the features that made them memorable)?

- Why did you remember and draw certain land marks on the sketch map (i.e. what were the features that made them memorable)?
- How did your way-showing tool (digital map, paper map, signage only) influence the cognitive map you drew?

\section{Distance estimation task}

To assess participants' survey knowledge estimated Euclidean distance between landmarks, the participants were given multiple pairs of landmarks that were all on the list of those they had to find. The Euclidean distance was described to them as "the straight-line distance between the two landmarks." They were asked to score the Euclidean distance between each pair from 0 to 9 , where 0 meant next to each other (no distance) and 9 meant the longest distance. The participants received a unit of measure, which was the distance between South Bank Station and COWCH (which they had all just been to), as equal to 1 .

\section{RESULTS}

\section{Destination decision making}

Participants' utterances showed there were two main approaches to initial destination decision making in the wayfinding task. 36 participants decided to begin by walking to the closest destination, for example, "I first go to the City Hall because it is the nearest one." Two participants (one in the GPS group; one in the paper map group) decided to follow a clockwise route, for example, "I prefer to start from left and see the cathedral and go towards the other destination in the right" There was no significant association between group and participants' destination decision making.

\section{Wayfinding performance}

The average distance travelled to find all destinations helps indicate the effectiveness of the navigation aid on performance. Table 2 lists the average travel time, the average distance travelled, and the average walking speeds across each group of navigators. Average travel time is a less reliable indicator of performance, due to variability in breaks taken by the navigators. A one-way, between-subjects ANOVA was conducted which showed that the difference in the average travel times across the 
groups was not statistically significant at the $95 \%$ confidence level. But the average distance traveled was significantly different between groups as was their average walking speed $(F(2,35)=3.5, p<0.05)$.

Table 2 / Wayfinding performance of the three groups

\begin{tabular}{llll}
\hline Groups & $\begin{array}{l}\text { Average distance } \\
\text { travelled }(\mathbf{k m})\end{array}$ & $\begin{array}{l}\text { Average travel } \\
\text { time }(\mathbf{h})\end{array}$ & $\begin{array}{l}\text { Average walking speed } \\
\mathbf{( k m} / \mathbf{h})\end{array}$ \\
\hline GPS & 5.47 & $1: 46$ & 3.1 \\
\hline Paper map & 6.03 & $1: 47$ & 3.3 \\
\hline $\begin{array}{l}\text { Local signage } \\
\text { only }\end{array}$ & 6.47 & $1: 52$ & 3.4 \\
\hline
\end{tabular}

Post-hoc paired comparisons showed that the average distance travelled, as well as the walking speed of the local-signage-only group, were significantly greater than those of the GPS group $(p<0.05)$. However, statistically there were no significant differences in the average distance travelled and walking speed between the paper map group and the two other groups.

Participants' utterances showed that six participants in the paper map group and eight participants in the local-signage-only group asked for directions; no one in the GPS group asked for directions.

\section{Sketch maps}

All 38 sketch maps drawn by the participants were collected and analysed based on Lynch's five urban image elements (Lynch,1960). Thirty-two of the cognitive maps were drawn from a top-down view (see Figure 2a); only two of them were drawn from a side perspective (see Figure $2 b$ ). Four maps used a combination of both views (see Figure $2 c$ ). One participant's sketch map was too simple to be analysable as a cognitive map, so it was excluded from the cognitive map analysis.

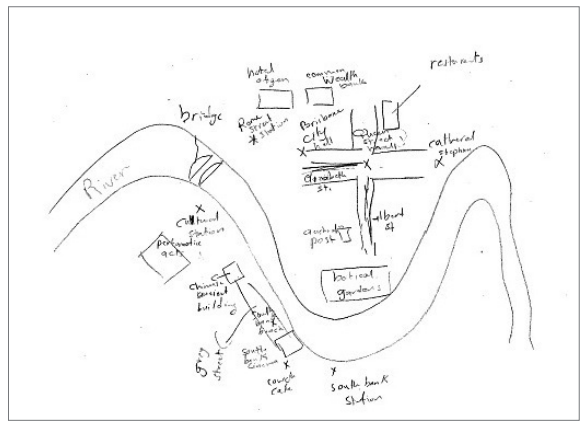

Figure 2a:

Top-down view

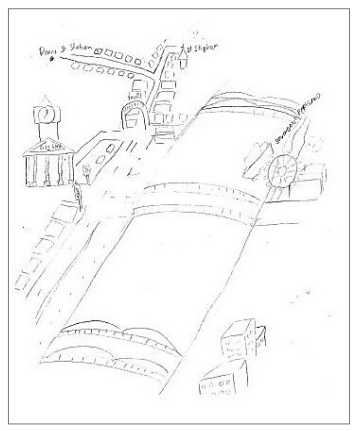

Figure 2b:

Side perspective

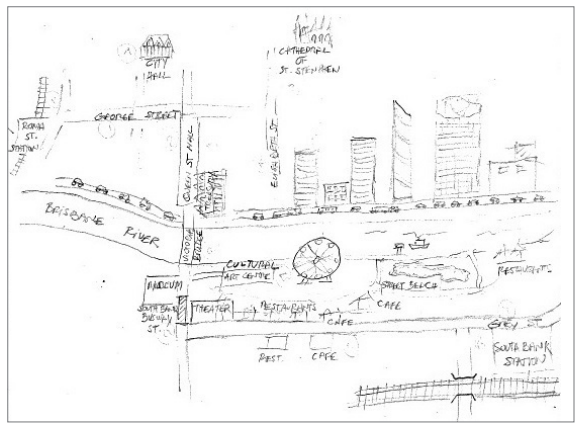

Figure 2c: /

A combination of top-down and side view 


\section{Analysis of landmark knowledge by group}

The number of remembered landmarks, such as transport stations, cafes, restaurants, shops, and banks, was considered a measure of landmark knowledge, point-like elements of the environment, across the groups (see Table 3, first row). A one-way, between-subjects ANOVA was conducted to compare the effect of each navigation aid on the landmark knowledge acquisition of participants. There was a significant difference in the number of remembered landmarks across the groups $[F(2,34)=6.50, p<0.01]$. Post-hoc paired comparisons showed that participants in the local-signage-only group remembered a significantly larger number of landmarks compared with the two other groups $(p<0.05)$. However, there was no significant difference between the numbers of landmarks mentioned by participants across the two other groups.

Table 3 / Mean (and standard deviation) for each variable by participants in the three groups

\begin{tabular}{llll}
\hline Variable & GPS Group (n=12) & $\begin{array}{l}\text { Paper map Group } \\
(\mathbf{n = 1 2})\end{array}$ & $\begin{array}{l}\text { Local-signage-only } \\
\text { Group (n=14) }\end{array}$ \\
\hline Landmark Knowledge & $7.4(3.5)$ & $8.6(3.4)$ & $10.1(7.9)$ \\
\hline Distance Estimation & $2.0(1.4)$ & $2.5(0.7)$ & $2.8(1.3)$ \\
\hline Street Name & $2.7(1.5)$ & $4.5(2.1)$ & $2.1(2.2)$ \\
\hline
\end{tabular}

\section{Analysis of route knowledge by group}

Route knowledge refers to the information participants gained about the paths they had taken, in terms of turns and directions, and the landmarks that existed along those routes (Werner et al., 1997). To assess the route knowledge gained by participants, we adapted Billinghurst and Weghorst's (1995) method, which suggests scoring the sketch maps based on three criteria: map goodness; object classes; and relative object positioning. All sketch maps were rated by two independent 'raters' who were familiar with the study area but unaware of the participants' identities and the type of navigational aids they used. They first rated the map goodness by using the question, "how good are the drawn routes in helping you navigate toward the destinations?" (Beime, 2007; Billinghurst \& Weghorst, 1995; Lukas et al., 2014). As we were particularly interested in route knowledge, we used route accuracy as the second rating criterion to represent object classes (Lukas et al., 2014). Route accuracy refers to any route in terms of "correct relations of the routes drawn in the sketch maps, turns and directions" (Lukas et al., 2014, p. 34). Relative object positioning was determined by the positioning of any landmarks on the drawn routes (Lukas et al., 2014; Parente, 2016). The inter-rater-reliability, Kendall's Tao, for rating of map goodness, route accuracy, and relative object positioning, was $0.70,0.65$, and 0.72 , respectively, suggesting good inter-rater agreement/reliability. The scores given to the maps were of ordinal value, so the Kruskal-Wallis $\mathrm{H}$ test was used. There was a difference in the ranking of map goodness drawn by each group that was approaching, but not quite reaching, statistical significance $[H(2)=$ $5.42, p<0.1]$. The results of Mann-Whitney U-tests (Table 4 , first row) showed that the map goodness of routes drawn by the paper map group was significantly higher than the GPS group, but there was no significant difference between the local-signage-only group and the two other groups.

There was a significant difference among the three groups in the case of route accuracy $[H(2)=7.37$, $p<0.05]$. The results of the Mann-Whitney U-test showed that the paper map group significantly outperformed the two other groups, while there was no significant difference between the local-signage-only and GPS groups (Table 4, second row).

There was a difference approaching significance between groups in terms of relative object positioning $[H(2)=5.17, p<0.1]$. According to the Mann-Whitney U-tests, the local-signage-only group performed significantly better than the GPS group, while there was no significant difference between the paper map group and two other groups (Table 4, third row).

Table 4/ The results of the Mann-Whitney U-test for the analysis of route knowledge between groups

\begin{tabular}{lllll}
\hline Category & Groups & Mean ranks & $\begin{array}{l}\text { Mann- } \\
\text { Whitney } \\
\text { U Test }\end{array}$ & P value \\
\hline Map & GPS, paper map & $9.29,15.71$ & 33.5 & .02 \\
goodness & GPS, local signage only & $10.58,15.23$ & 49 & .1 \\
& Paper map, local signage only & 14,12 & 66 & .5 \\
\hline Route & GPS, paper map & $7.92,17.08$ & 17 & .001 \\
accuracy & GPS, local signage only & $11.33,14.54$ & 58 & .2 \\
& Paper map, local signage only & $16.79,9.50$ & 32 & .006 \\
\hline $\begin{array}{l}\text { Relative } \\
\text { object } \\
\text { positioning }\end{array}$ & GPS, paper map & $10.88,14.13$ & 52.5 & .2 \\
& GPS, local signage only & $9.21,16.5$ & 32.5 & .01 \\
& Paper map, local signage only & $12.38,13.58$ & 70.5 & .6
\end{tabular}




\section{Analysis of distance estimation (survey knowledge) by group}

The survey knowledge in this paper is assessed by the capability of participants to estimate the Euclidean distances between pairs of destinations (Siegel et al., 1978; Thorndyke \& Hayes-Roth, 1982). As noted earlier, all participants were asked to score the Euclidean distance between some pairs of destinations using a score between 0 to 9 . The mean number of correct distance estimations for participants was slightly higher in the local-signage-only group and lowest in the GPS group (Table 2, second row). But the result of an ANOVA test did not show a statistically significant difference among the three groups of participants $(p>0.1)$.

\section{Results of the sketch mapping follow-up interview}

- Why are some paths more memorable?

Each group of participants was asked why some streets were memorable in their mental maps and drawn in their sketch maps, with results shown in Chart 1.

Chart 1 / Frequency of reasons for remembering paths by participants in the three groups

The most frequently mentioned reason for streets to be memorable for paper map and local-signage-only groups were attractions along the street (for example, the existence of shops, cafes and bars along Queen Street and Grey Street), and for the GPS group it was noticeable buildings along the street. This result shows the importance of landmarks and buildings in making a memorable path for navigators.

- Why are some buildings/landmarks more memorable?

Each group of participants was asked why some landmarks were memorable, with the results shown in Chart 2. The most frequently mentioned reason for a landmark to be memorable for all groups was because it was an eye-catching building in terms of color, building height or mass.

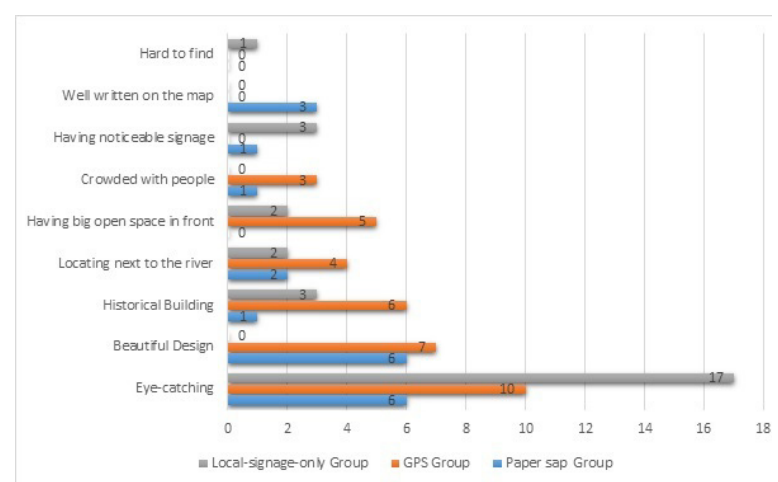

Chart 2 / Frequency of reasons for remembering landmarks in landmark knowledge task by participants in the three groups

- How did your way-showing tool influence the cognitive map you drew?

Chart 3 shows how different navigational aids helped participants create a mental map. For the paper map group, the most frequently mentioned influence was the map's role in helping them realize the overall shape of the city center as a peninsula, followed by locating the position of streets in relation to the river. For the local-signage-only group, being without a proper map was more confusing, preventing them from creating an accurate mental image. Compared with the paper map group, participants in the GPS group found their wayfinding tool more confusing and less helpful for creating a cognitive map; however, a few of them found it influential in estimating distance and remembering street names (not in line with the post-wayfinding tests results). 


\section{Analysis of the think-aloud data}

Analysis of think-aloud utterances, used to understand how people interact with space during a wayfinding task while using different navigational aids, can provide new understanding of the reasons behind the poor spatial knowledge acquisition of GPS users.

\section{Using environmental cues in wayfinding performance}

All groups were asked to think aloud and verbalize their thoughts about the wayfinding process, the buildings, streets, the signs, the maps, their feelings and whatever else came to their minds. To get more insight into the influence of environmental features on wayfinding behaviour, participants' reasons for choosing a street segment or any side of the street during the navigation task were extracted from the think-aloud protocols.

Table 5 shows the participants' preferences for taking a street segment, or even a side of the street, based on their utterances. Diverse route selection criteria were mentioned by the three groups of participants, including:

a) Physical characteristics of the road, such as being straight, short, a highway or a major road. For example, "I take this street because it is wide" (Group: local-signage-only); "I take North Quay because I see it directly goes to the city hall” (Group: paper map); "I think this way is the shortest one" (Group: paper map).

b) Being comfortable for pedestrians due to having shade or pedestrian roads. For example, "I will go on the left side because it is shady" (Group: GPS); "I stay in this side because it has wide pedestrian road" (Group: local-signage-only).

c) Type of space along the street, such as green areas, a river, shops and cafes, or any attraction. For example, "I take the right one because I think I can pass through the parkland as well" (Group: GPS); "I am going to the right side because of those stores and cafes" (Group: Paper map); "I choose the left because it looks nice" (Group: local-signage-only).

d) The number of cars, for example, "There is busy with cars, so I go there" (Group: local-signage-only);
"I think I can get through this, the street on the right one has no car" (Group: paper map).

e) The crowd on the street, for example, "I will continue here because here is less people" (Group: GPS); "I am fine with the left side of the street because I see a lot of people" (Group: paper map).

f) Green light, for example, "I prefer to turn right, the light is green; it is better than waiting for front cross" (Group: paper map).

The results of a Kruskal-Wallis $\mathrm{H}$ test showed that the three groups differed significantly in using environmental cues during navigation $[H(2)=6.69, p=0.035]$.

Table 5 / The participants' environmental preferences for taking a street. The percentage within condition are shown in parentheses

\begin{tabular}{llll}
$\begin{array}{l}\text { Environmental } \\
\text { Cue }\end{array}$ & \multicolumn{1}{c}{ GPS n(=12) } & Paper map $(\mathrm{n}=12)$ & $\begin{array}{c}\text { Local signage only } \\
(\mathrm{n}=14)\end{array}$ \\
Shade & $\mathbf{1 4 ( 1 . 2 0 )}$ & $14(0.98)$ & $8(0.49)$ \\
\hline River & $3(0.21)$ & $4(0.28)$ & $7(0.42)$ \\
\hline Avoiding the crowd & $6(0.42)$ & 0 & 0 \\
\hline Following people & $2(0.14)$ & $21(1.47)$ & $31(1.90)$ \\
\hline Attractions & $5(0.35)$ & $10(0.70)$ & $15(0.91)$ \\
\hline Major roads & 0 & $1(0.07)$ & $3(0.18)$ \\
\hline Pedestrian roads & $1(0.07)$ & 0 & $5(0.30)$ \\
\hline Straight routes & 0 & $4(0.28)$ & $1(0.06)$ \\
\hline Green light & 0 & 0 & $4(0.24)$ \\
\hline Green area & $8(0.56)$ & $6(0.42)$ & $4(0.24)$ \\
\hline More cars & 0 & $1(0.07)$ & $1(0.06)$ \\
\hline Less cars & $1(0.07)$ & $2(0.14)$ & 0 \\
\hline Shortest path & 0 & $5(0.35)$ & 0 \\
\hline Highway & 0 & 0 & $3(0.06)$ \\
\hline Total & $40(2.83)$ & $68(4.78)$ & $80(4.9)$ \\
\hline & & &
\end{tabular}

A Mann-Whitney U-test (see Table 6) shows the GPS group used the environmental cues significantly less than the local-signage-only group $(p=0.01)$, and there was a difference approaching significance between the GPS and paper map groups ( $p=0.05)$, while there was no significant difference between the paper map and local-signage-only groups $(p=0.5)$.

Comparing the participants' reasons for remembering streets with those for choosing a route segment reveals some similarities, such as attractions and locations next to the river.

On the other hand, some influential factors in route choice behaviour were not mentioned as reasons in the mental image generation, such as major roads and crowds for the local-signage-only group. On the contrary, some reasons were only mentioned for mental image generation but not for route choice behaviour, such as 
Table 6/ The results of the Mann-Whitney U-test for the analysis of total environmental cues mentioned by participants for choosing a street segment

\begin{tabular}{llllc}
\hline Category & Groups & Mean rank & $\begin{array}{l}\text { Mann-Whitney } \\
\text { Test }\end{array}$ & P value \\
\hline $\begin{array}{l}\text { Total } \\
\text { environmental } \\
\text { cues }\end{array}$ & GPS, Paper-map & $9.83,15.17$ & 40 & .05 \\
& GPS, Local-signage-only & $9.54,16.89$ & 36 & .01 \\
& $\begin{array}{l}\text { Paper map, Local -signage- } \\
\text { only }\end{array}$ & $12.54,14.32$ & 72 & .5
\end{tabular}

major roads for the GPS group. Although the GPS group followed the crowd while navigating considerably less than the two other groups, the crowded streets that they passed through remained in their minds.

\section{Perceived landmarks}

From the think-aloud recordings, a count of the names of landmarks was extracted from transcripts for each group, for example, "I see a big wheel." There proved to be no significant difference in the number of landmarks mentioned across the groups $[F(2)=1.21, p=0.3]$.

\section{DISCUSSION}

The results confirmed the outcomes from similar previous studies (Chang, 2015; Ishikawa, 2012; Ahmadpoor \& Heath, 2018) which found that navigational aids would significantly impact people's wayfinding behavior and acquired spatial knowledge.

The first hypothesis of this study was supported. The acquired spatial knowledge significantly differed among the three groups. Regarding landmark recognition, the local-signage-only group performed significantly better than the two other groups. While surrounding spatial knowledge, including the local signage system, was the main source of wayfinding information for this group, the navigational assistance provided to the two other groups reduced their dependence on landmark knowledge when navigating. The paper map group performed better in terms of route accuracy than the two other groups, and the local-signage-only group more accurately located landmarks on drawn routes than the GPS group. The type of navigational aid had no significant impact on distance estimation performance, but the paper map group was more likely to remember the names of streets than the two other groups, presumably as the paper map users needed to look for the names on the map to locate themselves in the actual environment, and needed to see and understand the street names to know where to turn. This is cognitively more demanding. This result differed from that of Chang (2015); within which GPS users were more successful in street naming than the paper map users and the signage users; one possible reason could be the difference in methods used in 
the two studies. In our study, we separately defined a street naming task by asking participants to name the street names on the plain maps of the study area. But in Chang's study, street naming performance was assessed by counting the road names provided in drawn sketch maps.

The second hypothesis was partially supported as well. The think-aloud data showed that the GPS group used the environmental information in their surroundings, such as attractions or the river, significantly less than the two other groups. They only followed the turn-by-turn navigational instruction on the device (Bakdash et al., 2008; Burnett \& Lee, 2005; Farrell et al., 2003; Gaunet et al., 2001; Parush et al., 2007; Péruch et al., 1995). In addition, think-aloud utterances showed that the GPS group chose to avoid the crowd in order to interact with their device undisturbed, while following the crowd was used as a wayfinding strategy by the two other groups.

However, according to the think-aloud utterances, the GPS and Paper-map groups still observed landmarks. There was no significant difference in the number of landmarks mentioned (perceived) across the three groups. But the local-signage-only group had to rely on this landmark knowledge more and inscribed it in their spatial memory. In other words, the GPS and paper map groups were more often only observing and perceiving the urban environment, instead of exploring and conceiving it. This result showed that the reason behind the strong landmark knowledge acquisition when using no map is that in this method of wayfinding navigators have to rely on the existing landmarks in their surrounding environment to find their way. However, navigation by maps frees people from reliance on those urban elements, and they just perceive but do not conceive. For example, although the GPS users look at their surroundings and see the existing urban elements (as evidenced by perceived landmark data), they cannot remember them after the wayfinding task because they do not need to use them to navigate (as evidenced by analysis of the think-aloud data). Consequently, they gain poor spatial knowledge of their surroundings (as evidenced by sketch mapping and recognition tests). The combination of the cognitive mapping technique and the think-aloud method has re- vealed a new psycho-cognitive aspect, beyond that of previous studies, of the effects of navigational aids on wayfinding behaviour and spatial cognition

The importance of attractions and buildings in path and landmark recognition demonstrated in this study confirmed previous work (Long, 2008). This outcome suggests that map designers, whether digital or paper, should pay more attention to showing tourist attractions in an accurate way in order to catch the attention of navigators and make these sites more memorable. Firms like Google are developing mapping tools with increasing sophistication in terms of displaying building and landmark information. Furthermore, with 3D models of cities now commonplace, more information could be provided to the wayfinder. Augmented reality may offer significant advantages here, if systems are carefully designed to maximize not just immediate navigation needs but also spatial learning. Overall, the findings of this study suggest new ideas to improve the functionality of the navigational aids in terms of spatial knowledge acquisition. For example, putting an emphasis on the representation of noticeable buildings and urban attractions in maps can enhance the memorability of paths and improve the acquired spatial knowledge. Other implications include showing the location of urban signage on maps. Thus, instead of following the recommended route on the Google map, navigators would have an option to walk toward the urban signage and use this during navigation as well, offering an opportunity to use spatial knowledge while exploring the city. Figure 3 shows an example.

On the other hand, while navigational aids can help people to find their way, it is important that architects, urban designers and urban planners work together to design legible urban environments. Chart 2 provides helpful information regarding enhancing urban legibility and creating more memorable landmarks, such as using notable signage for the names of buildings or designing large open spaces in front of buildings.

There are several limitations of our research. As in similar studies, and due to a lack of budget, we were unable to continually observe participants and trust that participants followed the instructions provided to them throughout their wayfinding task. However, the voice 

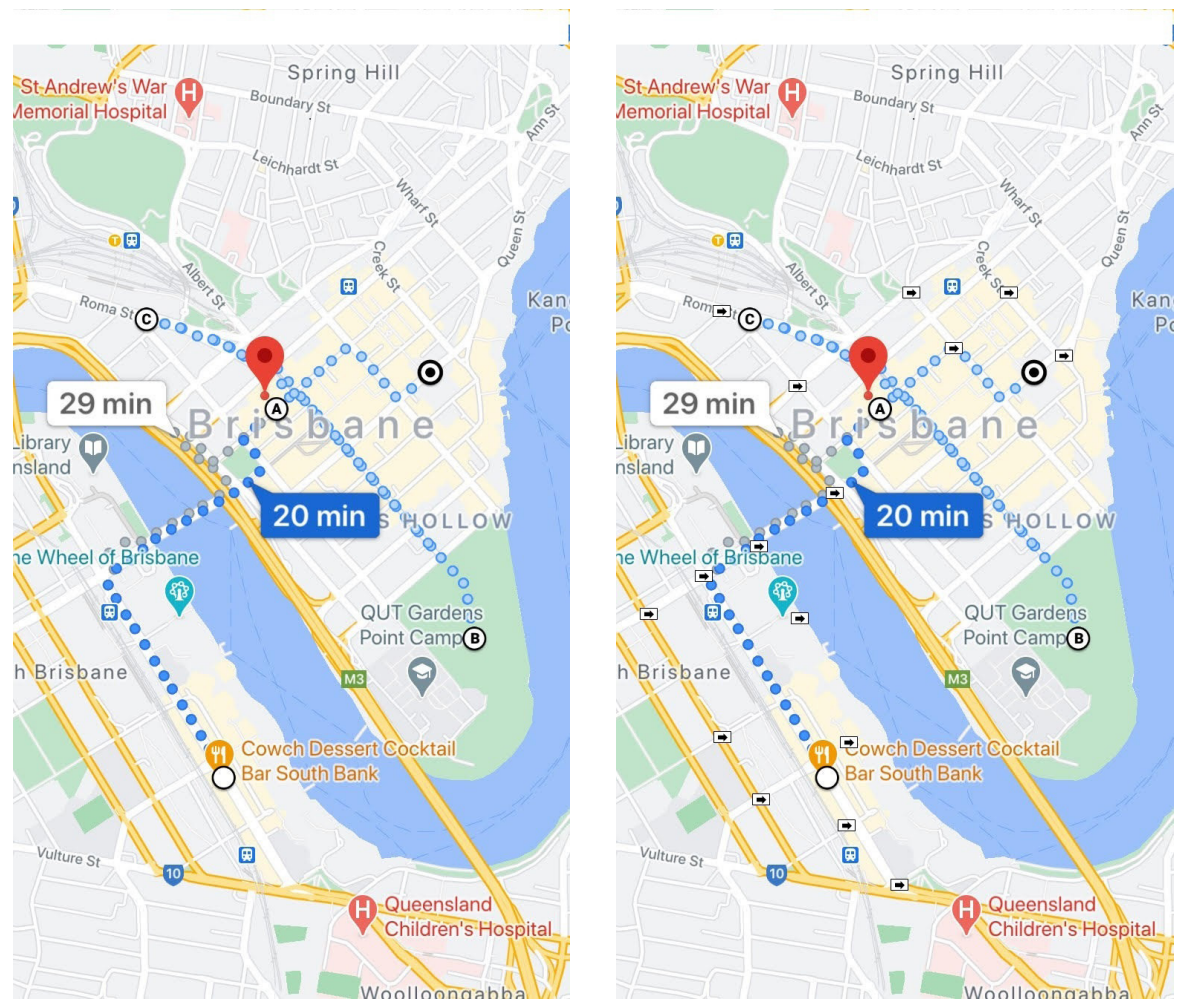

Google Maps app before (left) and after representing the urban signage (right)

recordings give us confidence that they did so. The quality of the sketch maps can be influenced by the drawing ability of participants. In addition, we used even numbers of raters for rating the sketch maps, although the agreement between raters was so high it suggests that using odd numbers of raters can strengthen the certainty of the result.

Methodologically, the study showed the value of including the think-aloud model in such research designs. It provided useful insights into landmark knowledge and route knowledge formation. In addition, to answer the research question we used slightly improved cognitive mapping methods compared with previous studies, such as distance estimation and street naming tasks. As GPS-based smartphone apps and similar technology improve, we need to continue to develop methods that help us observe behavior, capture acquired spatial memory, and understand how and why such memories are created.

Some issues remain unresolved. There are many options for spatial memory testing, but, as we found, respondent burden and costs are high if one includes most of them. If one had to reduce the set of tests conducted, it would be difficult to discern which tests would "best" help researchers understand particular issues of wayfinding effectiveness, spatial cognition, and memory.

For practitioners, there remains a need to continue to improve 
urban wayfinding systems, regardless of the increasing use of digital navigation. Practitioners may wish to explore ways in which the wayfinding systems that cities are installing in the built environment can better interact with digital wayfinding. They may also wish to disrupt GPS navigators and encourage them to make other route choices. How these outcomes might best be achieved has been little explored as yet.

\section{REFERENCES}

Ahmadpoor, N., \& T. Heath. 2018. “Data and GPS systems: Comparing navigation and landmark knowledge between gps users and non-GPS users." In Data, Architecture and the Experience of Place, edited by A. Karandinou. London: Routledge.

Bakdash, J. Z., Linkenauger, S. A., \& Proffitt, D. (2008). Comparing decision-making and control for learning a virtual environment: Backseat drivers learn where they are going. Proceedings $O f$ The Human Factors And Ergonomics Society Annual Meeting 52(27), 2117-2121. SAGE Publications.

Beirne, M. (2007). The impact of narratives on update and change of an existing cognitive map, Library and Archives Canada [Doctoral dissertation, Carleton University]

Billinghurst, M. \& Weghorst, S. (1995). The use of sketch maps to measure cognitive maps of virtual environments. Proceedings of Virtual Reality Annual International Symposium . 40-47.

Burnett, G., and Lee, K. (2005). The effect of vehicle navigation systems on the formation of cognitive maps. International Journal of Psychology. 40, 27-35.

Chang, H. H. (2015). Which one helps tourists most? Perspectives of international tourists using different navigation aids. Tourism Geographies, 17(3), 350-369.

Dillon, A., \& Vaughan, M. (1997). 'It's the journey and the destination': Shape and the emergent property of genre in evaluating digital documents. The New Review of Hypermedia and Multimedia, 3(1), 91-106.

Dutriaux, L., \& Gyselinck, V. (2016). Learning is better with the hands free: The role of posture in the memory of manipulable objects. PLoS One, 11(7).

Ericsson, K. A., \& Simon, H. A. (1980). Verbal reports as data. Psychological Review, 87(3), 215.

Farrell, M. J., Arnold, P., Pettifer, S., Adams, J., Graham, T., \& MacManamon, M. (2003). Transfer of route learning from virtual to real environments. Journal of Experimental Psychology: Applied, 9(4), 219.

Gardony, A. L., Brunyé, T. T., Mahoney, C. R., \& Taylor, H. A. (2013). How navigational aids impair spatial memory: Evidence for divided attention. Spatial Cognition and Computation, 13(4), 319-350.

Garling, T., Book, A., \& Lindberg, E. (1984). Cognitive mapping of large-scale environments: The interrelationship of action plans, acquisition, and orientation. Environment and Behavior, 16(1), 3-34.

Gartner, G., \& Hiller, W. (2009). Impact of restricted display size on spatial knowledge acquisition in the context of pedestrian navigation. In Location Based Services and TeleCartography II (pp. 155-166). Springer, Berlin, Heidelberg.

Gaunet, F., Vidal, M., Kemeny, A., \& Berthoz, A. (2001). Active, passive and snapshot exploration in a virtual environment: Influence on scene memory, reorientation and path memory. Cognitive Brain Research, 11(3), 409-420.

Grison, E., \& Gyselinck, V. (2019). La cognition spatiale pour repenser les aides à la navigation. LAnnee psychologique, 119(2), 243-278.

Golledge, R. G. (1978). Representing, interpreting, and using cognized environments. Regional Science, 41(1), 168-204.

Golledge, R. G. (1987). Environmental cognition. In D. Stokols \& I. Altman (Eds.), Handbook of Environmental Psychology, vol 1 (pp. 131-174). New York: John Wiley and Sons.

Golledge, R. G., (1999). Wayfinding behavior: Cognitive mapping and other spatial processes. Baltimore, Maryland: The Johns Hopkins University Press. 
Gras, D., Gyselinck, V., Perrussel, M., Orriols, E., \& Piolino, P. (2013). The role of working memory components and visuospatial abilities in route learning within a virtual environment. Journal of Cognitive Psychology, 25(1), 38-50.

Hegarty, M., \& Waller, D. A. (2005). Individual Differences in Spatial Abilities. In P. Shah \& A. Miyake (Eds.) The Cambridge Handbook of Visuospatial Thinking (pp. 121-169). Cambridge University Press.

Hegarty, M., Montello, D. R., Richardson, A. E., Ishikawa, T., \& Lovelace, K. (2006). Spatial abilities at different scales: Individual differences in aptitude-test performance and spatial-layout learning. Intelligence, 34(2), 151-176.

Hölscher, C., Büchner, S., Brösamle, M., Meilinger, T., \& Strube, G. (2007). Signs and Maps - Cognitive Economy in the Use of External Aids for Indoor Navigation. In Proceedings of the 29th Annual Cognitive Science Society (pp. 377-382). Austin, TX: Cognitive Science Society.

Ishikawa, T. (2016). Maps in the head and tools in the hand: Wayfinding and navigation in a spatially enabled society. In Community Wayfinding: Pathways to Understanding (pp. 115-136). Springer, Cham.

Ishikawa, T., Fujiwara, H., Imai, O., \& Okabe, A. (2008). Wayfinding with a GPS-based mobile navigation system: A comparison with maps and direct experience. Journal of Environmental Psychology, 28(1), 74-82.

Ishikawa, T., \& Montello, D. R. (2006). Spatial knowledge acquisition from direct experience in the environment: Individual differences in the development of metric knowledge and the integration of separately learned places. Cognitive Psychology, 52(2), 93-129.

$\mathrm{Li}, \mathrm{R}$. (2007). Human wayfinding and navigation in a large-scale environment: cognitive map development and wayfinding strategies. [ Doctoral dissertation, University of Saskatchewan, Canada] Retrieved from http://hdl.handle.net/10388/etd-12142007-162912

Lindberg, E. (1984). Acquisition of cognitive maps of large-scale environments, Dissertation, University of Ume.

Long, Y. (2008). The relationships between objective and subjective evaluations of the urban environment: Space syntax, cognitve maps, and urban legibility, (Doctoral dissertation, North Carolina State University).Retrieved from http://www.lib.ncsu.edu/resolver/1840.16/4411

Lu, Y. (2016). Creating a successful wayfinding system: Lessons learned from Springfield, Massachusetts [Master's thesis, University of Massachusetts Amherst]

Retrieved from https://scholarworks.umass.edu/larp_ms_projects/86/

Lukas, S., Mittelstaedt, V., Olaru, G., Sachser, C., Seibold, J., \& Huckauf, A. (2014). Effects of marked routes in You-are-here maps on navigation performance and cognitive mapping. American Journal of Applied Psychology, 3, 131-137.

Lynch, K. (1960). The image of the city. MIT press.

Meneghetti, C., Miola, L., Toffalini, E., Pastore, M., \& Pazzaglia, F. (2021). Learning from navigation, and tasks assessing its accuracy: The role of visuospatial abilities and wayfinding inclinations. Journal of Environmental Psychology, 75.

Münzer, S., Zimmer, H. D., Schwalm, M., Baus, J., \& Aslan, I. (2006). Computer-assisted navigation and the acquisition of route and survey knowledge. Journal of Environmental Psychology, 26(4), 300-308.

Parente, F. (2016). Moving through language: a behavioural and linguistic analysis of spatial mental model construction, (Publication No. 37620)[Doctoral dissertation, University of Nottingham]. Retreived from :http://eprints.nottingham.ac.uk/id/eprint/37620

Parush, A., S. Ahuvia, and I. Erev. (2007). Degradation in spatial knowledge acquisition when using automatic navigation systems." In Winter S., Duckham, M., Kulik, L., Kuipers, B. (Eds), Spatial Information Theory: Lecture Notes in Computer Science, (Vol. 4736,pp. 238-254). Berlin, Heidelberg: Springer.

Passini, R. (1984). Wayfinding in architecture. New York, NY: Van Nostrand Reinhold.

Piaget, J. \& Inhelder, B. (1967). The child's conception of space. W.W. Norton \& Company, Inc.

Péruch, P., Vercher, J. L., \& Gauthier, G. M. (1995). Acquisition of spatial knowledge through visual exploration of simulated environments. Ecological Psychology, 7(1), 1-20.

Ruginski, I. T., Creem-Regehr, S. H., Stefanucci, J. K., \& Cashdan, E. (2019). GPS use negatively affects environmental learning through spatial transformation abilities. Journal of Environmental Psychology, 64, 12-20.

Rushton, J. P., \& Ankney, C. D. (1996). Brain size and cognitive ability: Correlations with age, sex, social class, and race. Psychonomic Bulletin \& Review, 3(1), 21-36.

Siegel, A., \& White, S. (1975). The development of spatial representations of large-scale environments. Advances in Child Development and Behavior, 10, 9.

Siegel, A. W., Krasic, K. C., \& Kail Jr, R. V. (1978). Stalking the elusive cognitive map. Children and the Environment (pp. 223-258): Springer.

Techentin, C., Voyer, D., \& Voyer, S. D. (2014). Spatial abilities and aging: a meta-analysis. Experimental aging research, 40(4), 395-425. 
Thorndyke, P. W., \& Hayes-Roth, B. (1982). Differences in spatial knowledge acquired from maps and navigation. Cognitive Psychology, 14(4), 560-589.

Vaez, S., Burke, M., \& Yu, R. (2020). Visitors' wayfinding strategies and navigational aids in unfamiliar urban environment. Tourism Geographies, 22(4-5), 832-847.

Vandenberg, A. E. (2016). Human wayfinding: Integration of mind and body In R.H. Hunter, L.A. Aanderson, B.L. Belza (Eds.), Community wayfinding: Pathways to understanding (pp. 17-32). Springer International Publishing.

Willis, K. S., Hölscher, C., Wilbertz, G., \& Li, C. (2009). A comparison of spatial knowledge acquisition with maps and mobile maps. Computers, Environment and Urban Systems, 33(2), 100-110.

Yadav, C. S. (Ed.). (1987). Perceptual and cognitive image of the city (Vol. 12). Concept Publishing Company.

Yu, R., \& Gero, J. (2015, July). Design patterns from empirical studies in computer-aided design. [Paper presentation]. In International Conference on Computer-Aided Architectural Design Futures, Sao Paulo, Brazil (pp. 493-506). Springer, Berlin, Heidelberg.

Zhao, M., \& Warren, W. H. (2015). How you get there from here: Interaction of visual landmarks and path integration in human navigation. Psychological Science, 26(6), 915-924. 